\title{
Poverty Alleviation and Millennium Development Goals Implementation in Bayelsa State
}

\author{
Akekere Jonah, Yousuo P.O.J \\ ${ }^{1}$ Department of Economics Niger Delta University, Wilberforce Island Bayelsa State \\ ${ }^{2}$ Actuary, Publication, Research and Development Unit Nigeria Social Insurance Trust Fund (NSITF), Yenagoa, \\ Bayelsa State Branch
}

\begin{abstract}
The study investigates the impact of the Millennium Development Goals (MDGs) implementation on poverty reduction in Bayelsa state. We examined by comparison the level of achievements of the Millennium Development Goals in Bayelsa State before and within its implementation. We employed a single objective; to examine if there has been a reduction in poverty with the implementation of the MDGs. We used both Primary and Secondary data and a non parametric data analysis (Chi-square) in the analysis. And that the state is yet put achieve this goal (poverty reduction), that there is no significant different of the populace income level before and within the implementation period and we recommend that attention should be given to poverty reduction strategies, by injecting more resources to the programme considering the fact the programme is at its terminal stage.
\end{abstract}

Keywords: Millennium Development Goals, Poverty rate, Income, simple percentage, income security.

\section{Introduction}

In 1992, the Earth summit in Rio de Janerio issued the famous agenda 21, which in its forty chapters provided the framework for international understanding of and co-operation on the issue of sustainable development. Notably, agenda 21 recognized combating poverty as a basic condition for ensuring sustainability: social, economic and even sustainable environment. Since 1992, international agreements on the key issues of sustainable development have deepened and consensus on the urgent need to combat poverty in its many forms arisen. A number of world conferences organized by the United Nations following the Rio Earth Summit discussed the so-called International Development goals, which were meant to help focus and co-ordinate the efforts of donor countries, International Change Agencies (ICA), and the governments of developing countries themselves. In September, 2000, many of the goals were incorporated into the resolutions of United Nations' Millennium Development Goals through the General Assembly in New York (also called Millennium Summit) and endorsed by 189 countries as Millennium Development Goals. Development is far more complex than only economic growth or the quantitative accumulation of national capital. It is also the qualitative transformation of a whole society, a shift to new ways of thinking and correspondingly, to new relations and new methods of production. The transformation which will qualify for development must be one that will benefit most people, improve their quality of life and give them more control over their destinies. Thus development as a comprehensive process of change has to involve most of the population and cannot be imposed from outside the country.

Goal 1 is to reduce the proportion of people living in extreme poverty on less than a dollar a day. Bayelsa state an integral part of Nigeria which is a signatory to the MDGs pact, and thus is required to achieve the MDGs by 2015 if it must develop or be seen as a developing state. As a new state, Bayelsa is facing the challenges of high dependency ratio, lack of social overhead, unemployment and unskilled labour force, which call for a comprehensive human resource development and utilization to reduce mass unemployment and poverty to enhance development.

To be developed and remain developed has been the aspiration and desire of every nation. Scholars and development economists have over the years formulated theories, policies, set goals and targets to achieve development. The hallmark of setting goals is to achieve them on record time. Global goals are expected to be achieved by all nations although penalties are not imposed for their non achievement but concerted and collaborative efforts are required. Bayelsa State is one of the smallest states, in terms of population, with a monthly Federal allocation that ranks third in the Federation. Ordinarily, the state could easily achieve the MDGs, considering the resources at her disposal. What is not too clear is the performance of the state in achieving the set goals; what specific areas could be identified as the targets achieved or otherwise. It is based on this backdrop that we carried out this study; the implication of the MDGs implementation on poverty reduction in Bayelsa State. The study is guided by the following objectives: 
- To examine if there has been poverty reduction in Bayelsa State as a result of the implementation of the MDGs programme.

The study concentrates on assessing the level of Bayelsa state south-south Nigeria has achieved in the Millennium Development Goals goal one reduction of half proportion of people living in extreme poverty. The study covers the entire eight local government area of the state from 2000 to 2011 , with a sample of 400 individuals drawn from the respective Local Government Area.

\section{Literature Review}

The review of literature on the Millennium Development Goals have shown that, a number of countries have achieved major successes in fighting poverty, improving school enrolment and child health, expanding access to clean water, strengthening control of malaria and tuberculosis and increasing access to HIV treatment. These successes have taken place in some of the poorest countries, demonstrating that the MDGs are indeed achievable with the right policies, adequate levels of investment and international support. However it also revealed that progress has been uneven and without additional efforts, several of the goals are likely to be missed in many countries. In study by IRIN (2010), on poverty and hunger reduction, reveals that Ghana is set to become the first country in Africa to halve poverty and hunger before 2015. To Bello and Hakim (2009), posited that, the MDGs will not be achieved in Nigeria under the current trends. Commenting on the MDGs, according to Shetty (2010), represent an unprecedented promise to address global poverty and health to education and living standards to be met by 2015. However, its achievement is in doubt. The United Nations has issued a clear warning that "many of the MDGs will not be met in time unless efforts are radically ramped up".

Studies by Agnor et al (2006), white and Blondal (2007)and Easterly (2009) doubtfully acknowledged the achie vement of MDGs targets in Sub-Saharan Africa. Bello and Hakim (2009) observed that the poverty rate which is measured as proportion of the population living below one dollar per day. In another study by Goldman Sachs (2007) argued that in the whole of the African continent only two countries have the potentials to likely achieve some of the targets. These countries are Ghana and Egypt. Putting the statistics straight Egypt had reduced poverty Rate from $4.5 \%$ in 1991 to $2 \%$ in 2005 and under weight children from $10.4 \%$ in 1990 to $7.5 \%$ in 2008 , while Nigeria's poverty rate (headcount) increased from $49.2 \%$ in 1993 to $64.4 \%$ in 2004 and under weight children reduced from $35.7 \%$ in 1990 to $28 . \&$ in 2003 (United Nations 2009).

As pointed out by Easterly (2009), the MDGs were meant to be benevolent tools for advocacy, for greater development in and for poor countries, particularly in Africa. According to Timothy (2009), Nigeria would require a whooping four trillion naira annually, beginning from 2009 to 2015 to be able to tackle and reduce poverty only by $50 \%$. This implies that more capital is required to cut poverty by half in Nigeria by the target date.

Literature review on MDGs reveals that a good number of countries have achieved major success in fighting poverty reduction. This has also taken place in most less developed nations. In Nigeria and Bayelsa in particular the challenges of achieving this goal is enormous/severe, and literature on MDGs are not much, however, we are optimistic that, with the available resources Bayelsa State will soon realize this goal before the termination of the programme.

\section{Method of Study}

The study employed a primary and secondary data sources from the National Bureau of Statistics (NBS) 2011, questionnaire administration and the State Ministry of Budget and Economic Planning. We collected data related to household (individual) income from 1990-2010. The sources of these data are seems to be productive in research of this nature.

We used the Chi-square $\left(\mathrm{X}^{2}\right)$, a non parametric test to test the validity or otherwise of the research questions. We adopted this method of data analysis because is most suitable for the type of data, the aim of the study and it general acceptability and ease of usage.

The formula for the chi-square $\left(\mathrm{X}^{2}\right)$ test statistic is given below as:

$\mathrm{X}^{2}=\sum_{i=1}^{n} \frac{(f o-f e) 2}{f e}$

With $(\mathrm{r}-1)(\mathrm{c}-1)$ degree of freedom and

$\alpha$ Level of significance

Where:

$\mathrm{X}^{2}$ is the chi-square symbol (tool)

$\sum$ is summation sign

$\mathrm{i}=1$ is the observation where the summation begins

$\mathrm{n}$ is the observation at which the summation ends

fo is the observed frequency 
fe is the expected frequency

$r$ is the number of rows in the contingency table

$\mathrm{c}$ is the number of columns in the contingency table.

\section{Data Presentation and Analysis}

We presented the data in respect to the research questions in the questionnaire. Analyzing the question "has there been a reduction in the number of people living under the poverty line between 1990 and 2010?

Table 1a: $\quad$ Has your income improved over the period $1990-2010$

\begin{tabular}{|l|c|c|c|}
\hline \multicolumn{1}{|c|}{ Response } & Yes\% & No\% & Total\% \\
\hline Brass & $18(5.88 \%)$ & $12(3.92 \%)$ & $30(9.8 \%)$ \\
\hline Ekeremo & $19(6.21 \%)$ & $15(4.90 \%)$ & $34(11.11 \%)$ \\
\hline Kolokuma/Opokuma & $29(9.48 \%)$ & $11(3.59 \%)$ & $40(13.07 \%)$ \\
\hline Nembe & $33(10.78 \%)$ & $10(3.27 \%)$ & $43(14.05 \%)$ \\
\hline Ogbia & $25(8.17 \%)$ & $15(4.90 \%)$ & $40(13.07 \%)$ \\
\hline Sagbama & $30(9.8 \%)$ & $8(2.61 \%)$ & $38(12.42 \%)$ \\
\hline Southern Ijaw & $20(6.54 \%)$ & $19(6.21 \%)$ & $39(12.75 \%)$ \\
\hline Yenagoa & $31(10.13 \%)$ & $11(3.60 \%)$ & $42(13.73 \%)$ \\
\hline Total & $\mathbf{2 0 5 ( 6 6 . 9 9 \% )}$ & $\mathbf{1 0 1 ( 3 3 . 0 1 \% )}$ & $\mathbf{3 0 6}(\mathbf{1 0 0} \%)$ \\
\hline Mean & $\mathbf{2 5 . 6 2 5}$ & $\mathbf{1 2 . 6 2 5}$ & \\
\hline
\end{tabular}

Source: Field Survey 2011.

Table 1b: non parametric (Chi-square) analysis of MDGs impact on income improvement

Software use: SPSS 16.0

\begin{tabular}{|c|c|c|}
\hline $\boldsymbol{f}_{\boldsymbol{\theta}}$ & $\boldsymbol{f}_{\boldsymbol{e}}$ & residuals \\
\hline 8 & 23.5 & -15.5 \\
\hline 10 & 23.5 & -13.5 \\
\hline 11 & 23.5 & -1.5 \\
\hline 12 & 23.5 & -11.5 \\
\hline 15 & 23.5 & 6.5 \\
\hline 18 & 23.5 & -5.5 \\
\hline 19 & 23.5 & 14.5 \\
\hline 20 & 23.5 & -3.5 \\
\hline 25 & 23.5 & 1.5 \\
\hline 29 & 23.5 & 5.5 \\
\hline 30 & 23.5 & 6.5 \\
\hline 31 & 23.5 & 7.5 \\
\hline 33 & 23.5 & 9.5 \\
\hline Total 306 & $\mathrm{X}^{2}=45.595$ & $\mathrm{X}_{0.05}^{2}=21.0$ \\
\hline & Asymp sig .000 & $\mathrm{DF}^{2}=12$ \\
\hline
\end{tabular}

The test of average of the analysis is that there is an increase in income of household after the implementation of the programme in the state. The chi square test also shows a very high chi-square value indicates that there is a significant difference in the opinion of the respondents that their incomes have improved over the period 1990-2010. That is, there is a significant improvement in the income of majority of the respondents. To obtain some level of precision, we sought the opinion of respondents on their income levels the result is presented in table $1 \mathrm{~b}$ above.

With reference to section A of the questionnaire which requires stating the respondent's income level per month, for 1990, 2000, and 2010 the responses after analyzing is presented as follows:

Table 1c: $\quad$ Income Level in Bayelsa State

\begin{tabular}{|c|c|c|c|c|c|}
\hline \multirow{2}{*}{$\begin{array}{c}\text { Respondents } \\
\text { Income Level Per Month }\end{array}$} & \multirow[b]{2}{*}{1990} & \multirow[b]{2}{*}{2000} & \multirow[b]{2}{*}{2010} & \multicolumn{2}{|c|}{ Remarks } \\
\hline & & & & Naira Per Day & $\begin{array}{c}\text { Dollar Per Day at } \\
160 / \$\end{array}$ \\
\hline$\$ 1,000-10,000.00$ & 140 & 100 & 20 & $\$ 32.00-\$ 323.00$ & $\$ 0.2-\$ 2$ \\
\hline$\$ 21,000-\$ 30,000.00$ & 28 & 47 & 35 & $\$ 677.00-\$ 970.00$ & $\$ 4.2-\$ 6$ \\
\hline$\$ 31,000-\$ 40,000.00$ & 31 & 31 & 71 & $\$ 1000-\$ 1,290.00$ & $\$ 6.3-\$ 8$ \\
\hline$\$ 50,000-$ Above & 18 & 40 & 165 & $\$ 1,613.00$ and above & $\$ 10$ and above \\
\hline
\end{tabular}

Source: From Field Survey 2011. 
Figure 4: Showing various income level brackets for 1990, 2000 and 2010

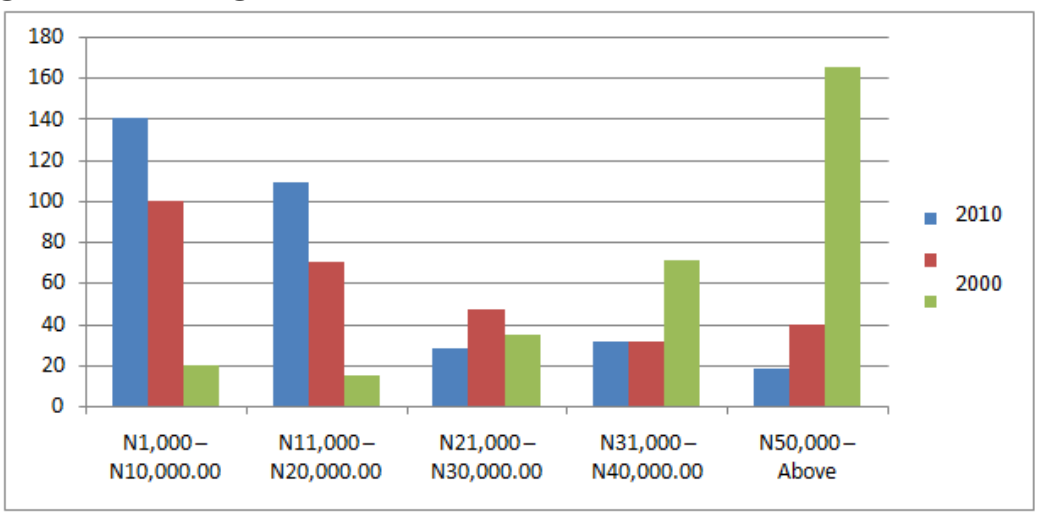

\section{Discussion of Findings}

This goal requires that, between 1990 and 2015 the proportion of people whose income is less than one dollar a day will be reduced by $50 \%$. This is still a mirage in the state. However from the survey conducted, there has been a positive shift on income level in the state. From the questionnaire it is revealed that in 1990, those whose income bracket was between N1,000 - 10,000 was very high up to 140 and by 2010, it has dropped significantly as only 20 respondents agreed they were in that bracket. Those whose income bracket are from $\mathrm{N} 40,000$ and above that is living on more than N1,000 daily showed improvement. What we also gathered is that though there seem to be relative positive shift on income level, the family size is not taken into consideration, if the family size is considered there will be nothing to write home on the perceived improvement on the respondent's income. From the study we can therefore conclude that while the respondents may claim of improvement in income but it does not reflect on the income per head of the family.

\section{Conclusion}

The relationship between the Millennium Development Goals implementation and poverty reduction in Bayelsa state is partly on course. Study reveals that poverty reduction by $50 \%$ of the population is far from being achieved in Bayelsa State. We therefore recommend; adequate attention should be given to poverty reduction strategies, by injecting more resources to the programme considering the fact the programme is at its terminal stage. It is crystally clear that there has been accrued revenue increase to the state due to its oil wealth, but the revenue has not been properly channeled to ensure full achievement of the MDGs. Resources should be effectively channeled to reduce the social and economic deprivation so as to enhance societal well being, joy, satisfaction fulfillment, contentment of human beings and service delivery. This is very significant because the MDGs are viable platform to develop the state.

\section{References}

[1]. Agenor, P; Nihal, B.; Emmanuel, P.M. and Karin, E.A. (2005): "Achieving the Millennium Development Goals in Sub-Saharan Africa", A Macroeconomic Monitoring Framework World Bank Policy Research Working Paper.

2]. Bello, M.A. and Abdulhakim R. (2009): "Future of Millennium Development Goals in Nigeria". Goldman Sachs Group Inc.

[3]. Easterly, W. (2009): "How the Millennium Development Goals are Unfair to Africa", World Development.

[4]. Goldman, Sachs (2007): Goldman Sachs Global Economics Research, the Goldman Sachs Group Inc.

[5]. IRIN (2010): "Ethopia - Ghana: MDGs Success Stories UN Office".

[6]. National Bureau of Statistics (NBS) 2008

[7]. Salil, Shetty (2010): "Human Rights are Key to the MDGs", Nairobi Kenya.

[8]. Timothy, G. (2009): "We Need 24 Trillion to Cut Poverty by Half”. Leadership Newspaper.

[9]. United Nations (2009): “Country Data, Retrieved July 31, 2009” from http:/mdgs.un.org/unsd/mdg/Data.aspx.

[10]. White, H. and Blondal, N. (2007): "Projecting Progress Toward the Millennium Development Goals", United Nations University, World Institute for Development Economic Research (UNU-WIDER, 2007). 